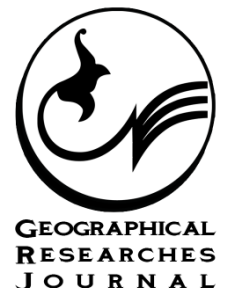

\title{
Presentation a Model for Explaining the Economic, Social, Cultural and Political Dimensions of Development in the Creation Creative City, Case Study: Isfahan City
}

\section{ART ICLE INFO}

\section{Article Type}

Original Research

\section{Authors}

Safavi Y. ${ }^{1} P h D$

Zarrabi A. ${ }^{2} P h D$

Soheilipour M.* $M A$

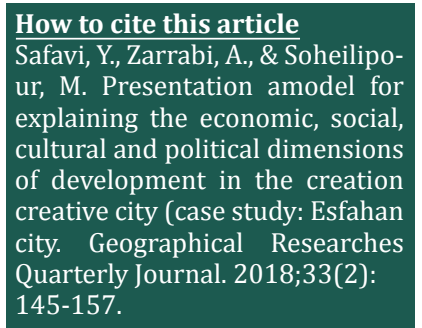

${ }^{1}$ Department of Political Geography, Faculty of Geography, Imam Hossein Uni-versity, Tehran, Iran ${ }^{2}$ Department of Geography and Urban Planning, Faculty of Geography and Planning, Isfahan University, Isfahan, Iran

*Department of Geography and Urban Planning, Faculty of shakhespajouh, Isfahan University, Isfahan, Iran

\section{*Correspondence}

Address: Department of Geography and Urban Planning, Faculty of shakhespajouh, Isfahan University, Isfahan, Iran

Phone: -

Fax: -

Mehdisoheilipour@gmail.com

\section{Article History}

Received: February 5, 2018

Accepted: -

ePublished: -

\begin{abstract}
A B S T R A C T
Introduction and Background During the evolution of urban life, what has taken a long way towards success and positive changes in the way of life in cities has been derived from innovative thought or evolutionary ingenuity. Today, the science of creativity in urban planning called creative city is one of the main factors for sustainable development and multilateral progress. Despite the progress of the last decade in urban management, the metropolis of Isfahan has had many problems including old industries, lack of creativity in changing the use of their unused spaces, traditional agriculture despite the water crisis, environmental pollution, lack of participation of elites in education, the existence of urban exhausted texture, and so on.

Aims The purpose of this research is to measure development indicators on the creation and development of a creative city in the metropolis of Isfahan.

Methodology The research method is applied in terms of purpose and descriptive survey nature. Data gathering was field study by using a questionnaire. The sample size was 384 which is calculated by Cochran formula. The 5-degree Likert spectrum technique was used to measure the value of development indicators of the creative city. Also, a single-sample t-test was used to compare the mean of variables.

Conclusion The results showed that in the economic indexes of the creative city, from the viewpoint of citizens, the highest and the lowest average are respectively "Improvement of business space by urban management" with a value of 3.99 and "Marketing of creative industries and branding" with a value of 3.83. In social indexes, the highest and the lowest mean are "Strengthening social institutions" with a value of 4.36 and "Human capital" with a value of 4.20. The highest and lowest mean of cultural indexes were identified as "Capital and cultural diversity" with a value of 4.30, and "Creative ideation" with a value of 3.96. Also, the highest and lowest mean of the indexes of the political dimensions of "Security and Stability" were 4.47 and "Tolerance" with 3.84 .
\end{abstract}

Keywords Creative City, Sustainable Development, Isfahan Creativity Model

\section{I T A T I O N L I N KS}

(Atefi \& Hatamialamdari; 2017) The effect of creative city indicator on the economic and social scale of metropolises ...; (Batabyal \& Beladi; 2016) The effects of probabilistic innovations on Schumpeterian economic growth in a creative ...; (Bolívar \& Rodríguez; 2018) Creative citizenship: the new wave for collaborative environments in smart ...; (Borén \& Young; 2017) Artists and creative city policy: Resistance, the mundane and engagement in Stockholm ...; (Branscomb, et al; 1999) Industrializing knowledge: University-industry linkages in Japan and the United ...; (Dorostkar; Farah; \& Majedi; 2016) Feasibility study on the formation of a creative area with industrial tourism theory (case study: ...; (Goldberg-Miller; 2018) Keeping creativity downtown: Policy learning from San Francisco, Seattle, and Vancouver for municipal cultural planning in ...; (Izadi, et al; 2016) Urban regeneration with emphasis on identification of creative city indicators ...; (Kakiuchi; 2016) Culturally creative cities in Japan: Reality and ...; (Landry \& Bianchini; 1995) The creative city ...; (Zarrabi, et al; 2014) Investigating the realizability of creative city ...; (Musterd; 2004) Amsterdam as a creative cultural knowledge city : Some conditions. Built Environment, ...; (Nazmfar, et al; 2017) Measuring the ranking of urban settlements of Ardabil province in terms of possessing the creative city ...; (Pourahmad, et al; 2017) Assessing the challenges and opportunities of creating a creative city in free trade zones (case study: ...; (Pourramezan, et al; 2016) City of knowledge: Future development strategy of Zanjan city ...; (Rabbani Khorasgani, et al; 2012) Investigating the role of social diversity in the creation of creative cities ...; (Sandercock; 2005) Interface: A new spin on the creative city: artist/planner ...; (Sarvar, et al; 2016) Analysis of the efficiency of urban neighborhoods in terms of indicators of the creative city ...; (Shaterian, et al; 2017) The effects of tourism power on infrastructure development and the creation of a creative city ...; (Thiel; 2017) Creative cities and the reflexivity of the urban creative ...; (Yigitcanlar \& Kamruzzaman; 2018) Does smart city policy lead to sustainability of cities? Land Use ... 


\section{ارائه مدلى در تبيين ابعاد اقتصادى، اجتماعى، فرهنكى و سياسى توسعه در تحقق شهر خلاق مطالعه موردى: شهر اصفهان}

مقدمه: در طى تكامل زندگى شهرى، آن جه موجب برداشتن گامهاى بلند بهسوى كاميابى و تغييرات مثبت در شيوه زيست

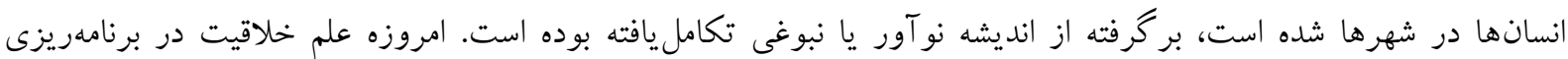

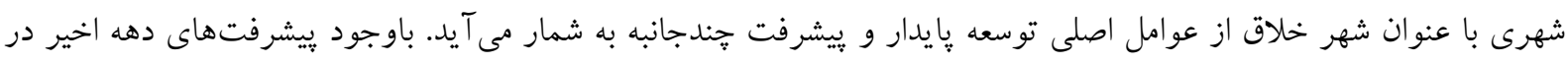

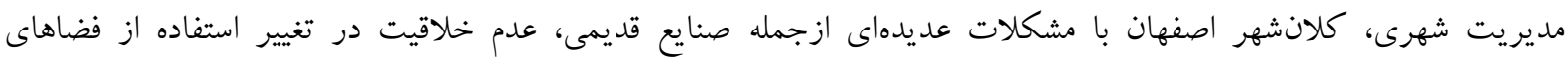

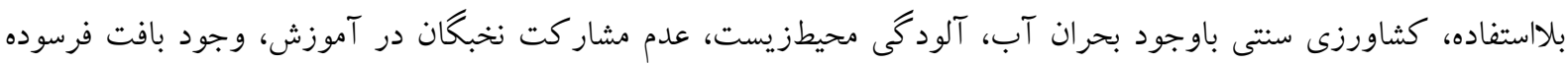
شهرى و غيره مواجه است.

اهداف: هدف از انجام اين يزوهش سنجش شاخص هاى توسعه بر ايجاد و توسعه شهر خلاق در كلانشهر اصفهان مىباشد.

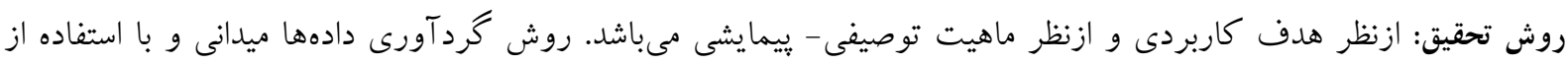

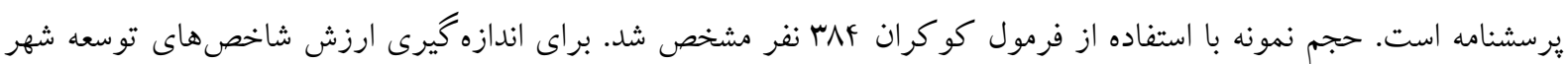

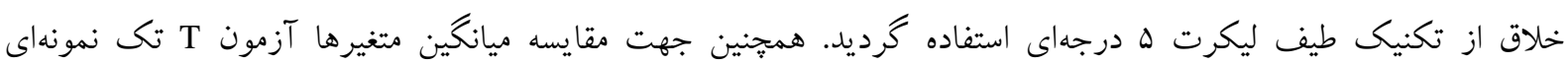
مورداستفاده قرار كرفت.

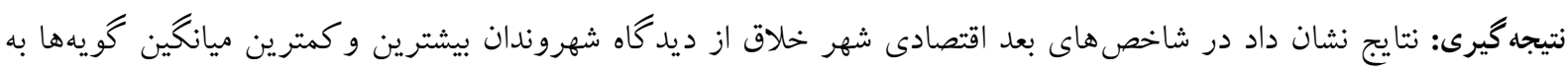

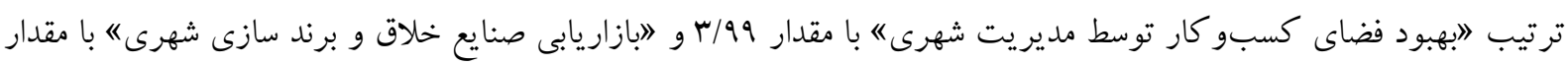

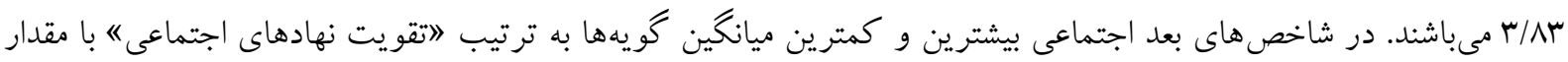

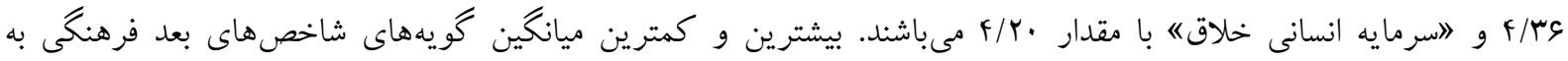

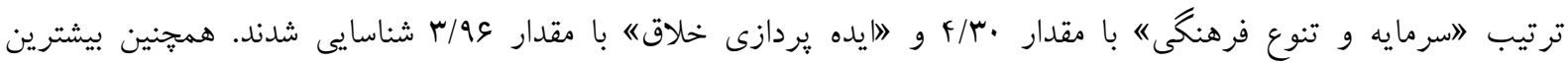

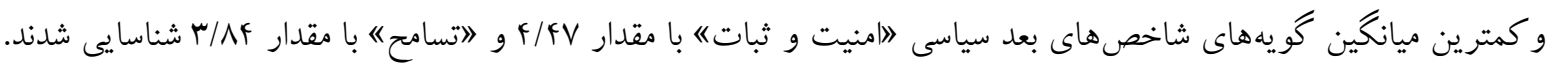
وازگان كليدى: شهر خلاق، توسعه پِايدار، مدل خلاقيت اصفهان 
در طول تاريخ آن خه موجب برداشتن گامهاى بلند بهسوى كاميابى و تغييرات مثبت در شيوه زيست انسانها شده، بركرفته

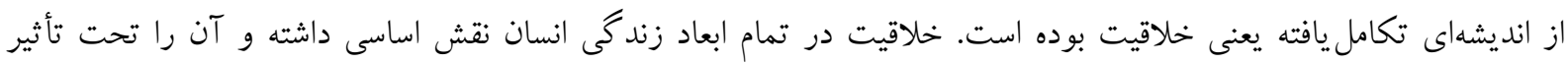

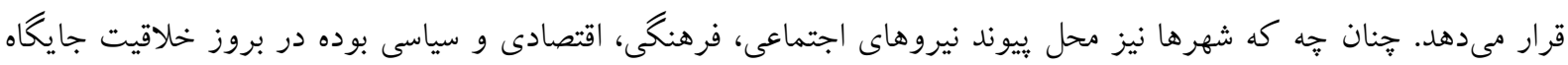

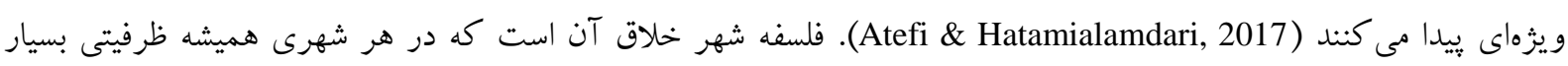

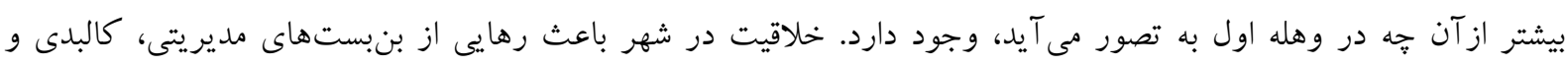

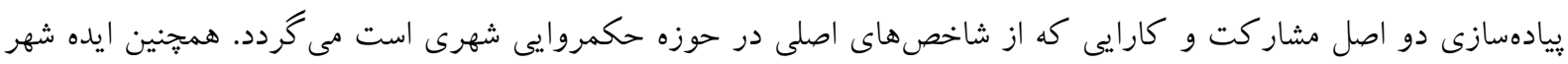

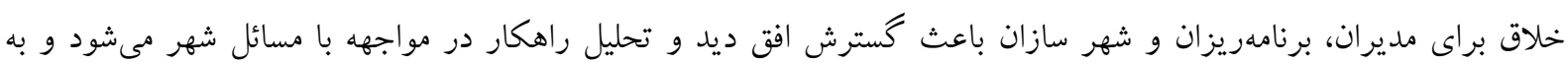

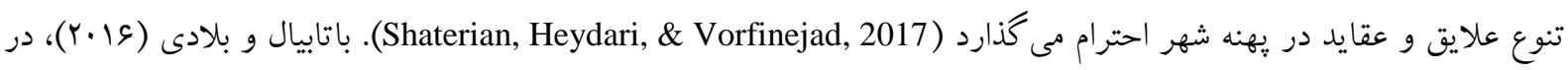

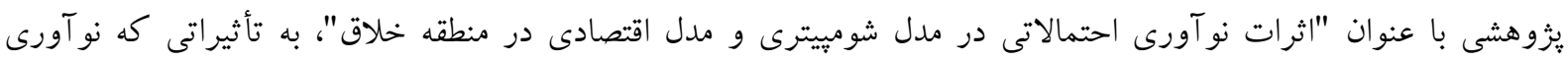

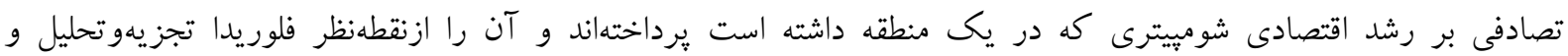

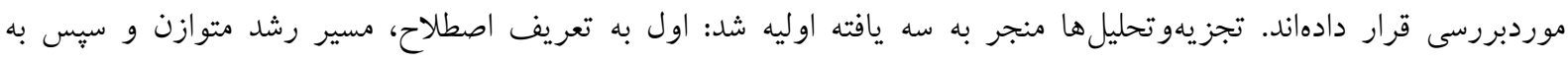

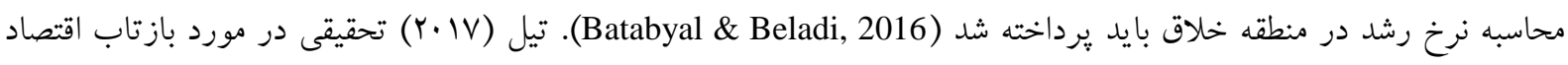

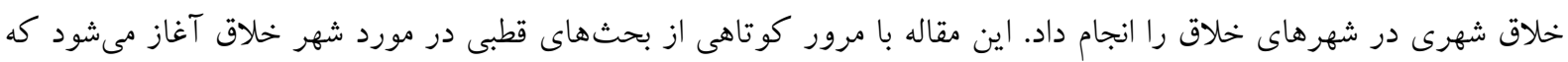

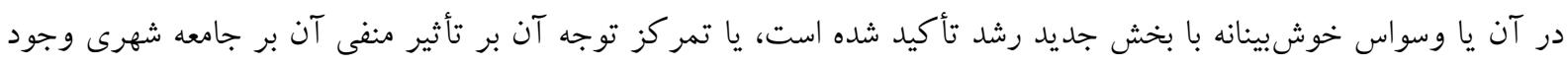

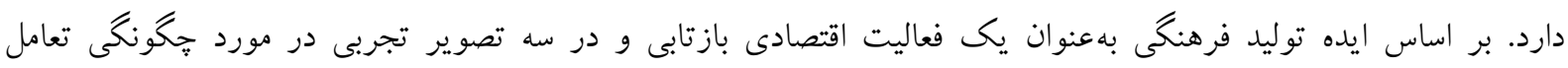

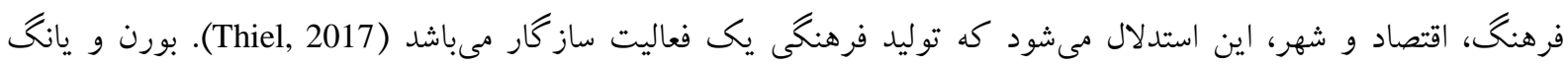

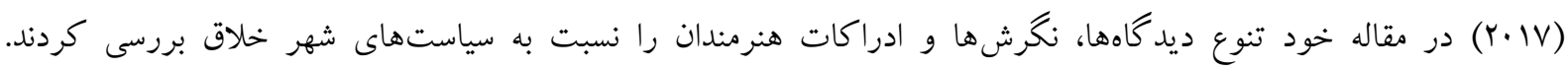

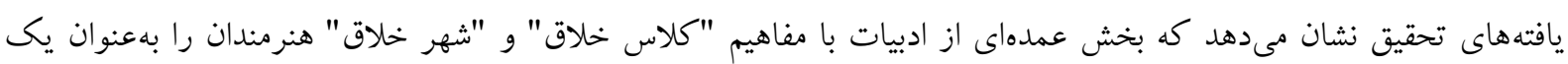

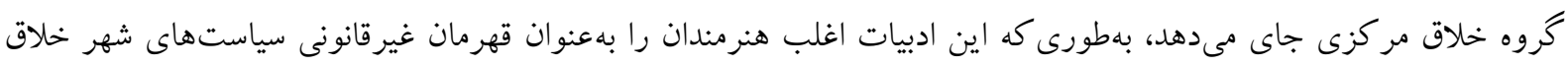

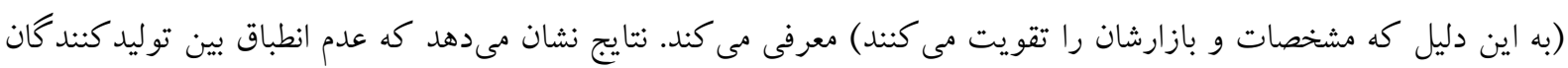

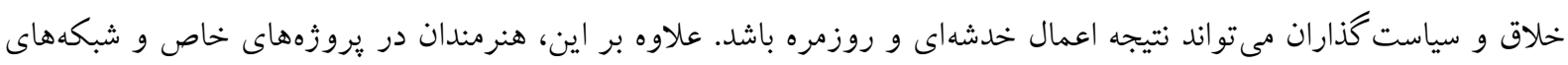

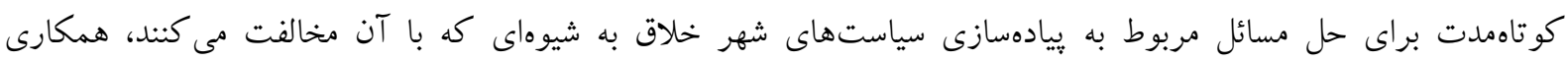

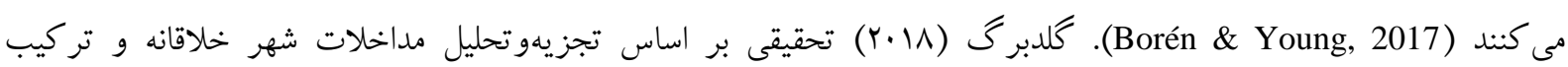
جارجوب نظرى انطباق سياست شهر تورنتو و درك سياست شهرهاى سان فرانسيسكو، سياتل و ونكوور انجام داد. نتايج نشان

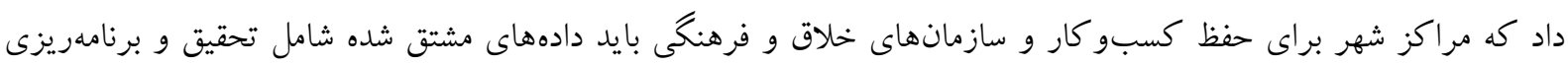

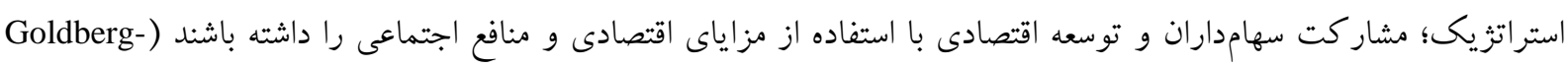

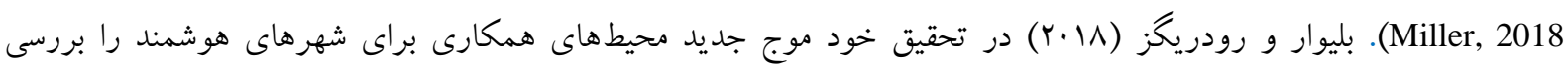

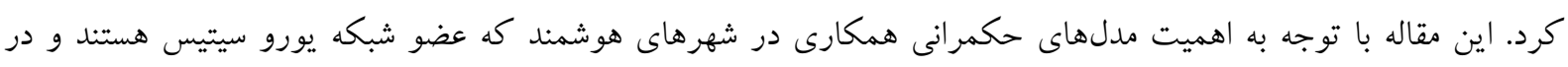

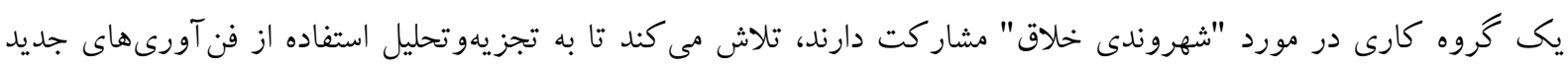

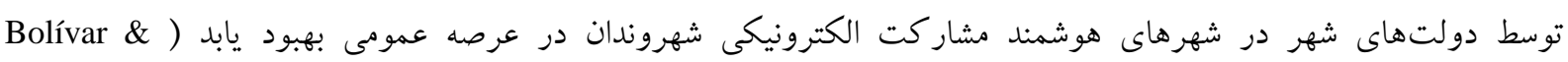

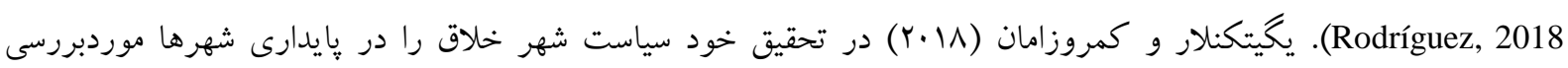

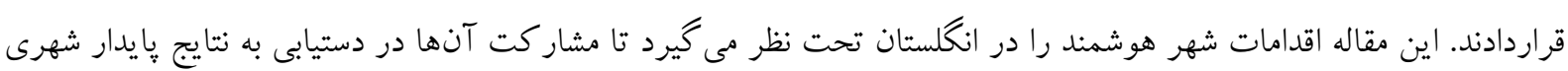




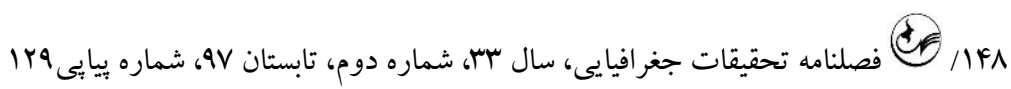
را بررسى كند. بررسى تغييرات ميزان انتشار دى اكسيد كربن در ها شهر انگلستان با استفاده از اختلاف سطح هوشمندانه شهر در

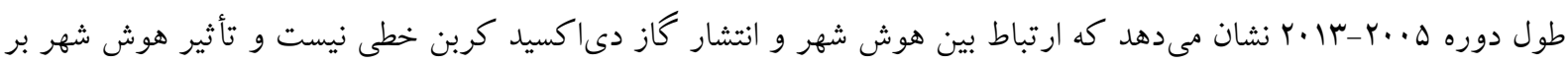

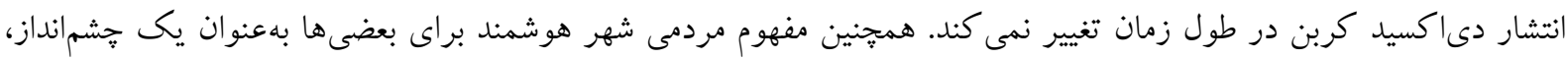

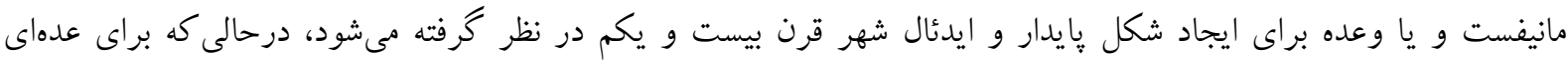
ديخر فقط يك تظاهر است (Yigitcanlar \& Kamruzzaman, 2018). ايزدى و همكاران (هوسا) در تحقيق خود به ارزيابى بافت تاريخى- فرهنكى شهر شيراز در ارتباط با شاخصهاى شهر

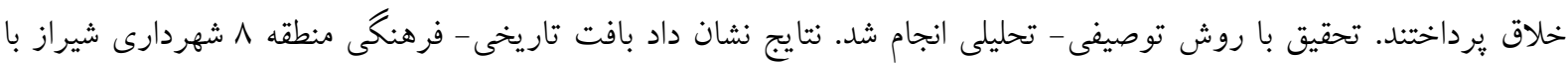

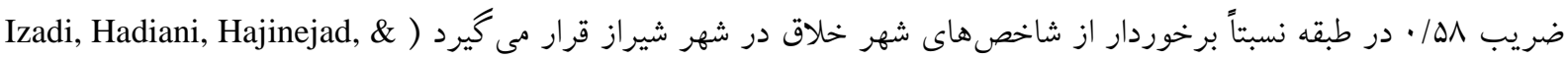

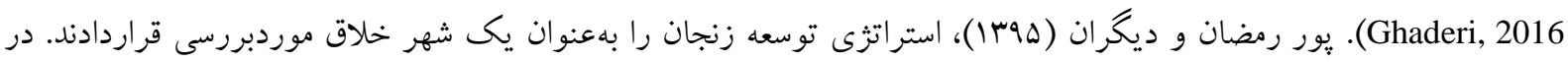

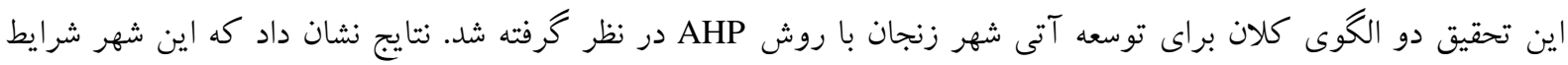
لازم براى تبديلشدن به يك شهر دانشبنيان را دارا مىباشد (Pourramezan, Pourhosein Roshan, \& Aliakbary, 2016).

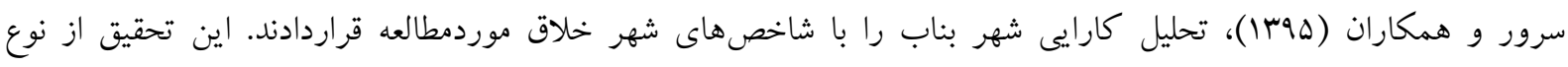

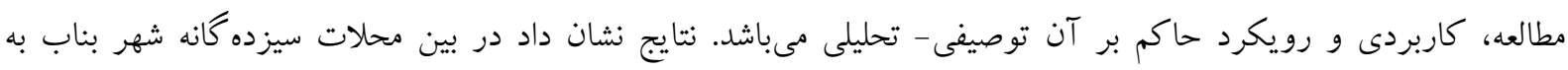

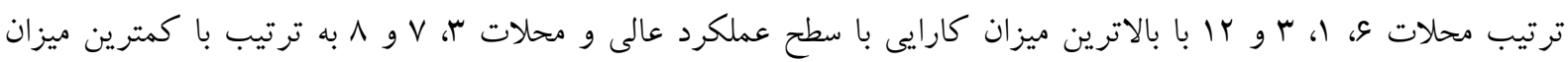
كارايى با سطح عملكرد ضعيف ازلحاظ شاخص هاى شهر خلاق هستند (Sarvar, Akbari, Amani, \& Taleshianbouhi, 2016).

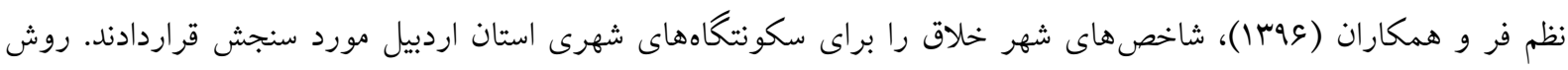

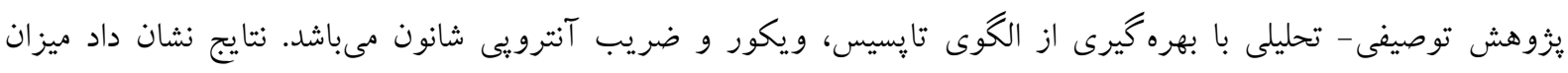

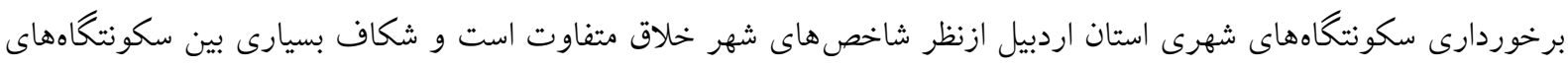

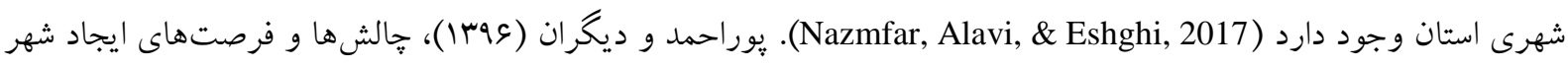

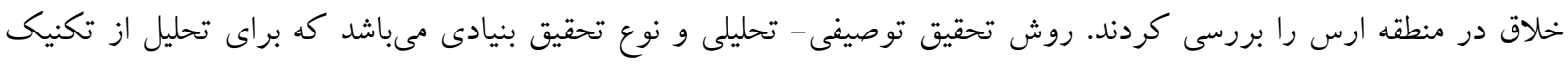

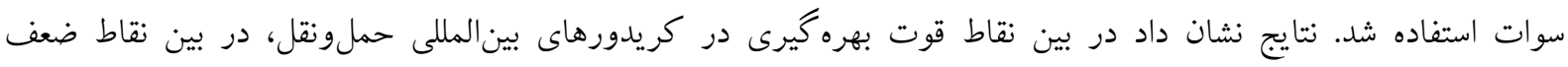

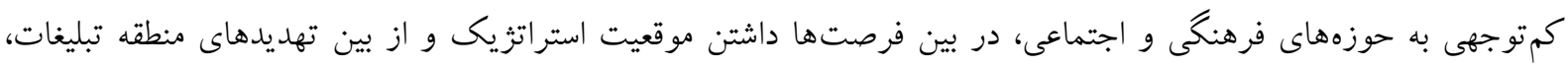
آثانس ها و بازاريابى محدود مهم ترين موارد هستند (Pourahmad, Hamidi, Farhadpour, \& Hoseinpour, 2017).

\section{مبانى نظرى}

مفهوم شهرها و وازه شهر خلاق

شهر خلاق: تا اواسط دهه •و99، ابتدا در بريتانيا و سِّ در آمريكا، مفهوم شهر خلاق تبديل به يكى پارادايم هنجارى و

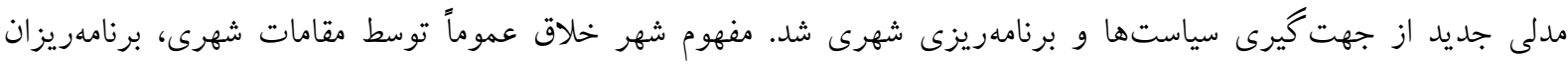

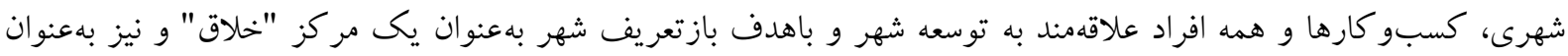

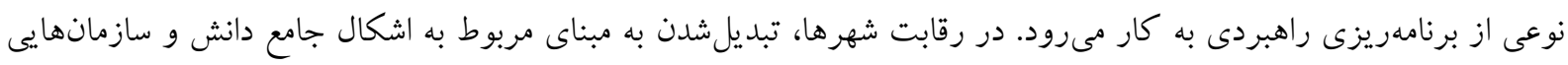

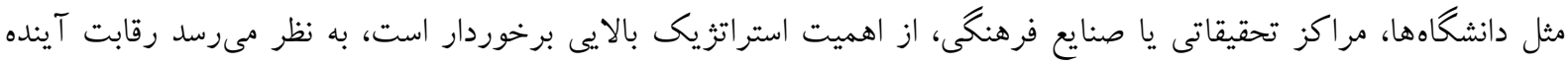

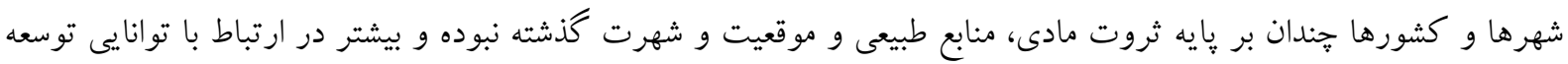
تصاوير و نمادهاى يرجاذبه و طراحى جذاب امروزى شهرهاست (Landry \& Bianchini, 1995). در يكى مفهوم شهر خلاق، 
شهرى است كه قادر است راهحل جديدى براى مشكلات روزمرهاش ارائه دهد و اين شهر داراى جذب سرمايههاى انسانى يا منابع انسانى خلاق است (Rabbani Khorasgani, Rabbani Khorasgani, Adibi Sedeh, \& Moazzeni, 2012). در شهر خلاق سعى بر آن است با توسعه شاخصهاى مختلف خلاقانه، مردم را به كار كردن با قوه تخيلشان تشويق كند كه

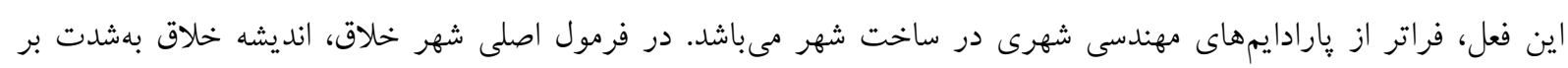

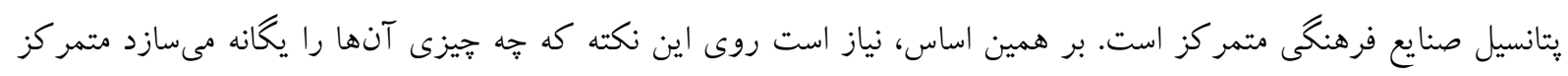
شوند. در اين زمينه مىتوان به يروزههاى هنرى و استفاده مجدد از ساختمانهاى قديمى به شكل خاص اشاره كرد. بايد توجه

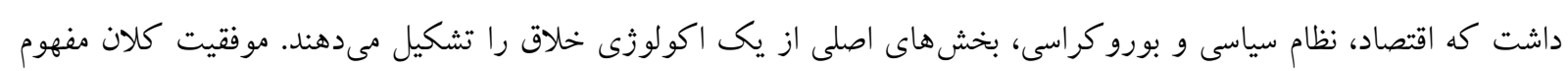
شهر خلاق، بهواسطه تغييرات كستردهتر اقتصادى و اجتماعى است كه درنتيجه آن، خلاقيت انسانى تبديل به يك عامل كليدى شده است. تغيير سبك زندكى و كار منجر به ايجاد طبقهاى جديد با عادات يا ويز گیىاى فرهنكى جديد شده كه بر ارزشها و و هنجارهاى جديد نظير فردگرايى، تنوع، انكيزش درونى، خود اظهارى و آزادى تمركز دارد. تعاريف خلاقيت شهرى بستكى به

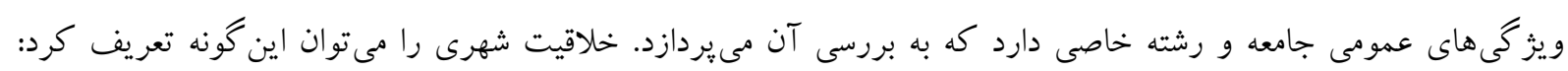

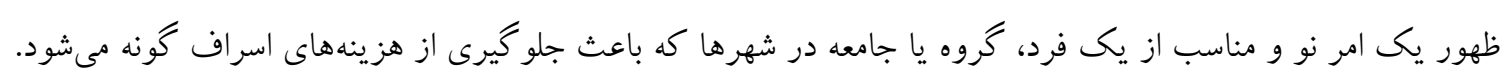
شهر خلاق بهصورت يك سيستم: در مناطق خلاق، نوآورى بهصورت يك مكانيزم و فرايند يويا با اجزا و زيرسيستمهاى

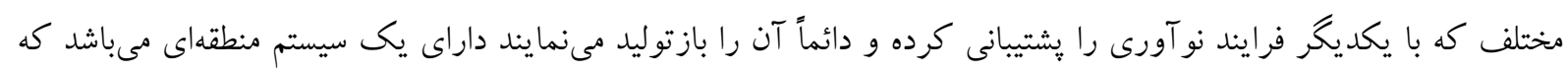

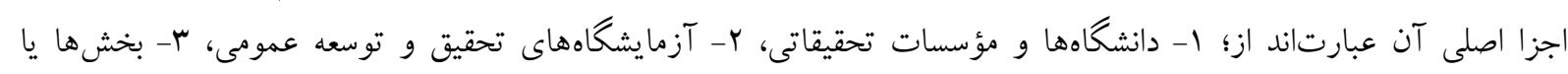
مراكز خصوصى تحقيق و توسعه، f- سيستم اطلاعات فناورانه: ثبت اختراع، استانداردها، انتشارات، بازار نياز و بيش،بينى إنى روندها، ه- خوشها (كروهى از شر كتها در هماهنكى و همكارى طولى و عرضى)، ع- سازمانهاى تبادل فن آورى: يارك هاى فن آورى، شبكههاى فن آورى، واسطهها و مشاور، V- امور مالى و سرمايهاى نو آورى: بانك ها، صاحبان كسبو كار،

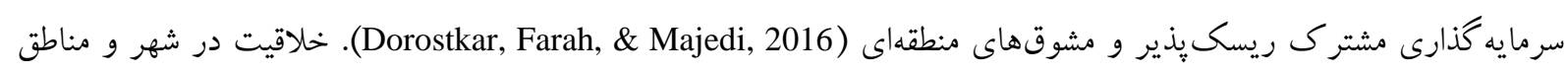

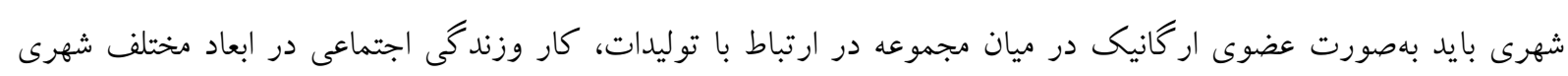
توسعه و كسترش يابد (Musterd, 2004). توسعه يايدار: توسعه شهرى جيست؟ ياسخ يك جمله است؛ كاهش فقر، افزايش در آمد و ايجاد تغيير در زمينه هاى اقتصادى،

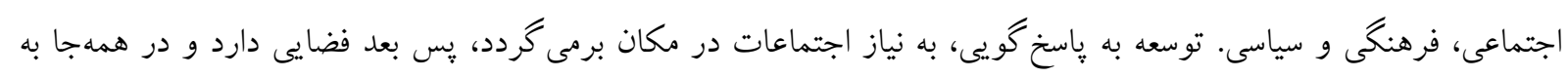
يك صورت اتفاق نمىافتد. مهمترين بحث در فضاى شهرى بحث عدالت اجتماعى و خدمات يكسان شهرى است كه توزيع نسبى حقوق، منابع و تخصيص منابع، ايجاد فرصت در برابر جامعه را شامل مىشود و در فضا متجلى مىشود. تخصيص منابع نه

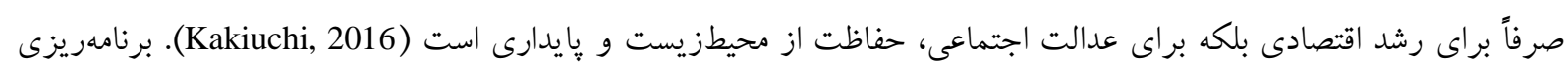

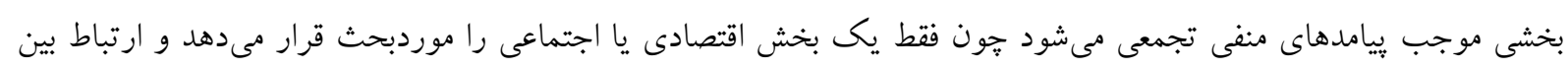

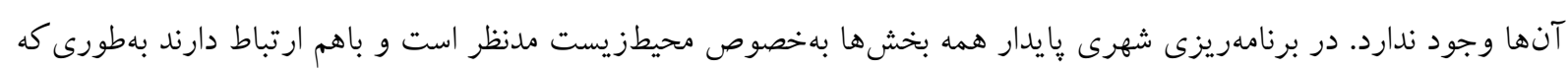
از مباحث مهم ييرامون مسائل شهرى، مفهوم توسعه يايدار شهرى و ارتباط آن با خلاقيت و طبقه خلاق است كه توسعهاى مبتنى بر نيازهاى واقعى و تصميم گيرىهاى عقلايى، با در نظر گرفتن ملاحظات مختلف اقتصادى، اجتماعى و زيستمحيطى محسوب

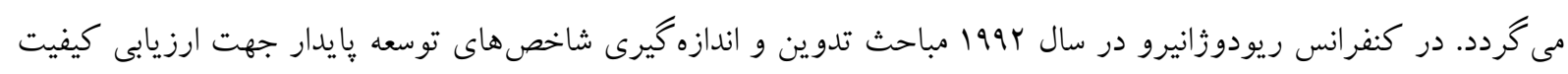

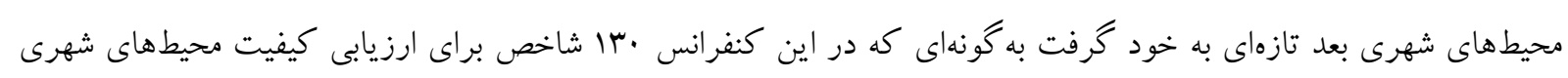
و رسيدن به توسعه يايدار شهرى مطرح شد كه اين شاخصها رابطه مستقيمى با شكل كيرى جامعه دانشمحور و شهر خهر خلاق دارند 
1/10.

(Sandercock, 2005) (خراكه شهر خلاق بهعنوان يك مكان با شكوفايى قوى هنر و فرهنگ، خلاقيت و نوآورى با به كار گيرى شاخص هاى توسعه پايدار است (Zarrabi, Mousavi, \& Bagherikashkouli, 2014).

\section{شاخصهاى سنجش خلاقيت شهر}

ريجارد فلوريدا از سال r. r. سه شاخص استعداد، فن آورى و قدرت تحمل (تسامح) را براى سنجش خلاقيت در يك شهر را

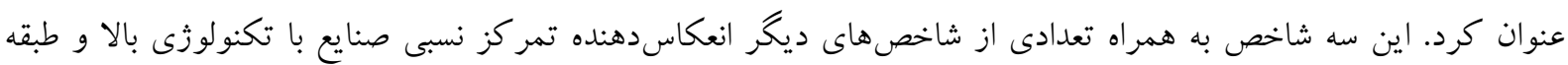

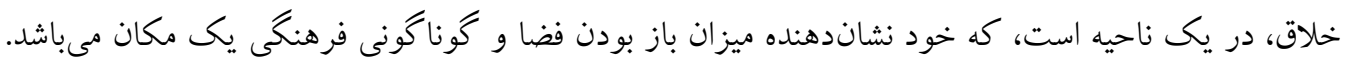

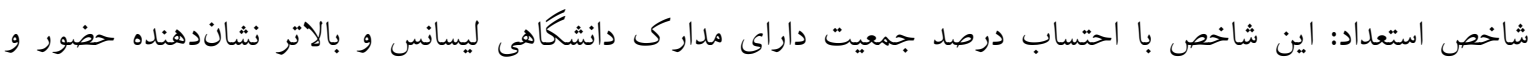

$$
\text { تمركز ميزان سرمايه انسانى در يك ناحيه است. }
$$

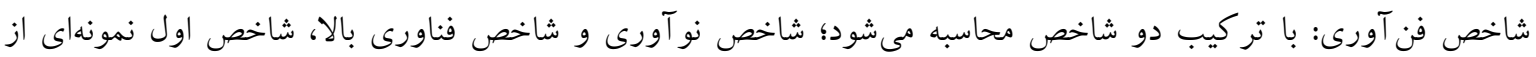

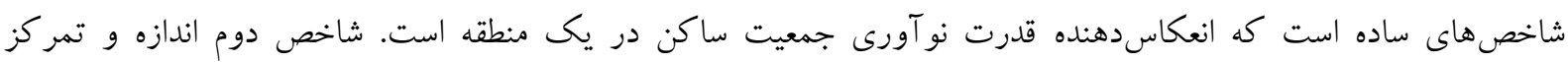

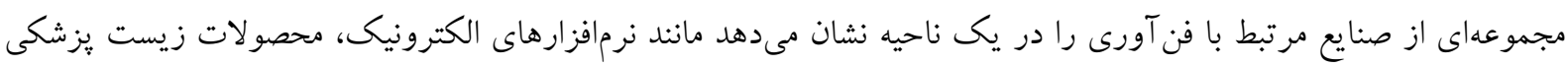

شاخص تسامح: با يكى شاخص تركيبى و متنوع اندازهيرى مىشود. همجيون تركيبى از شاخص زوجيت، شاخص سنتشكنى و شاخص ذوب فرهنكى است.

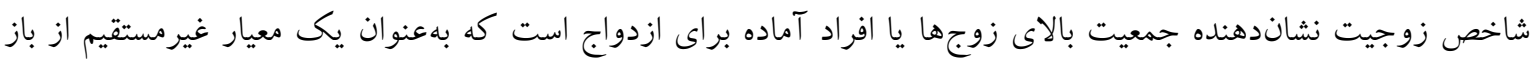

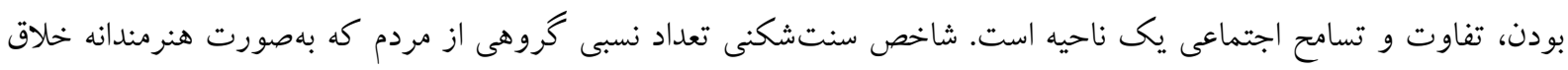

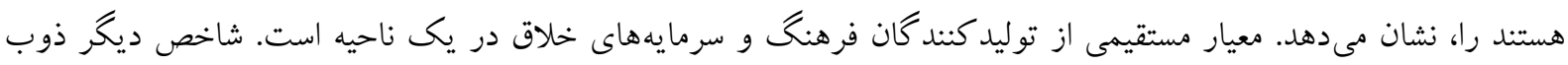

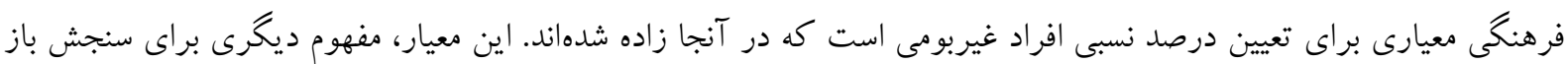

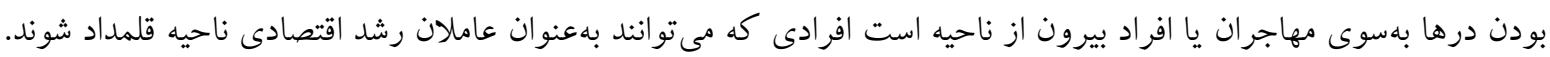

جدول ا- شاخصهاى خلاقيت يورو از ديدكاه فلوريدا

\begin{tabular}{|c|c|}
\hline شاخص & معيار \\
\hline شاخص خلاقيت يورو & جمع رتبه افراد مستعد، فن آورى و تلورانس تقسيمبر حداكثر رتبه ممكن \\
\hline شاخص استعداد يورو & 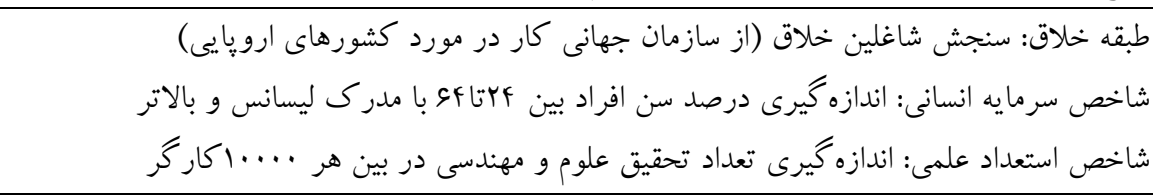 \\
\hline شاخص فن آورى يورو & 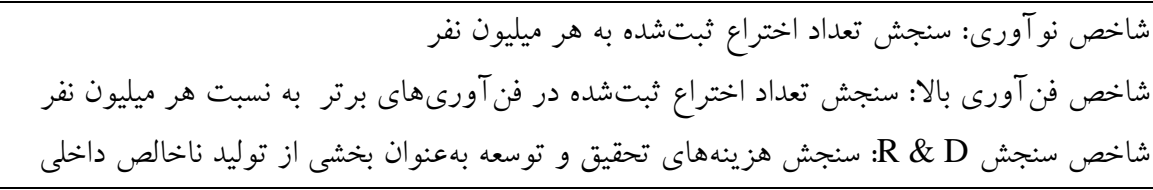 \\
\hline شاخص تسامح يورو & 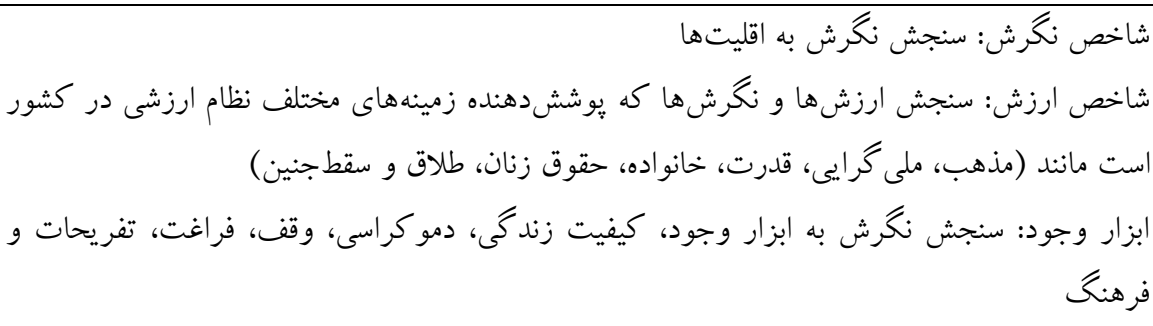 \\
\hline
\end{tabular}

منبع: (Branscomb, Kodama, \& Florida, 1999) 
اين تحقيق ازنظر هدف از تحقيقات كاربردى و ازنظر روش توصيفى - ييمايشى است. در تحقيق حاضر با توجه به اينكه

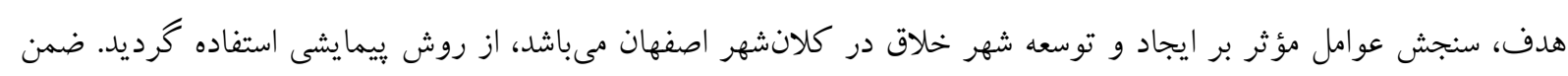

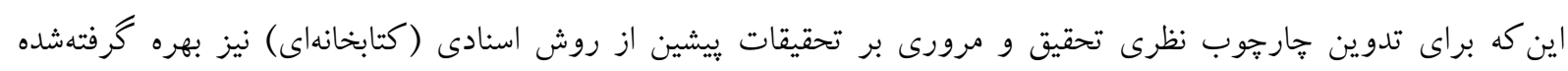

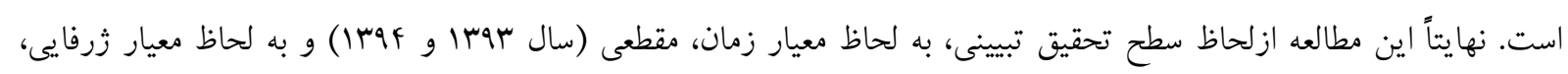

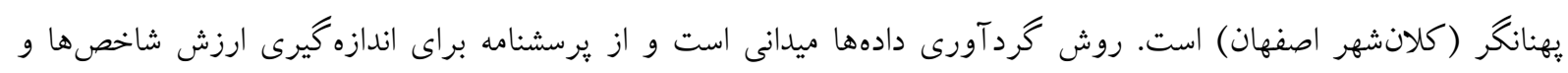
ابعاد مبتنى بر تكنيك طيف ليكرت هـ درجهاى بوده استون.

جامعd آمارى شهروندان

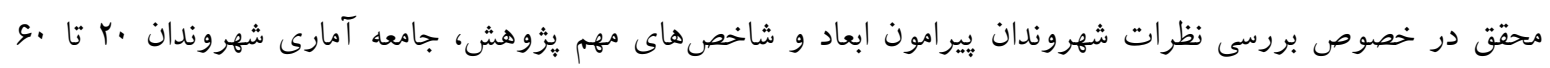

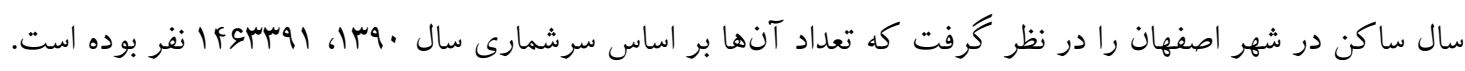

\section{حجم نمونه و شيوه نمونه گيرى از شهروندان}

براى تعيين حجم نمونه شهروندان شهر اصفهان با استفاده از فرمول كو كران اقدام گرديد. در تعيين اندازه نمونه و بهمنظور

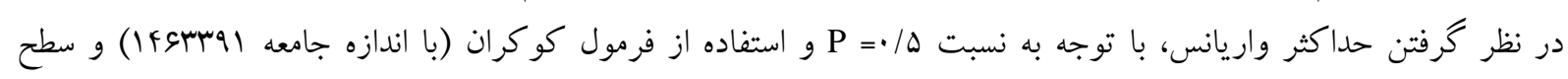

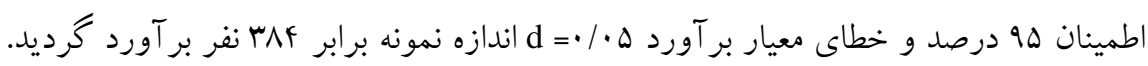

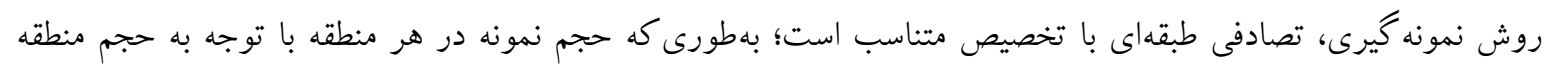

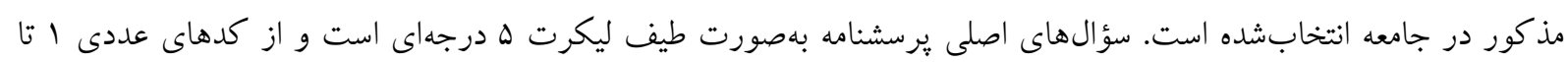

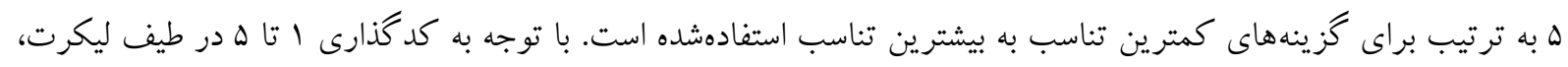

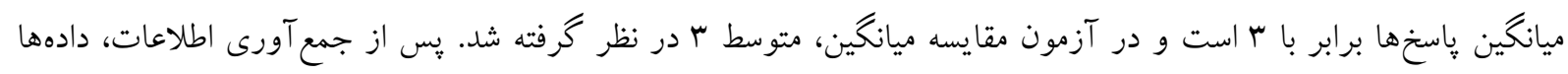

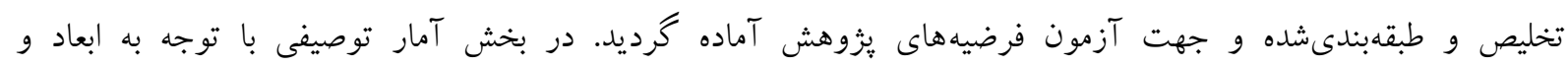

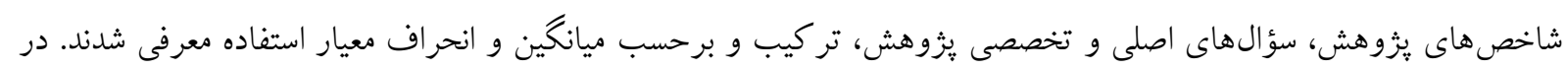

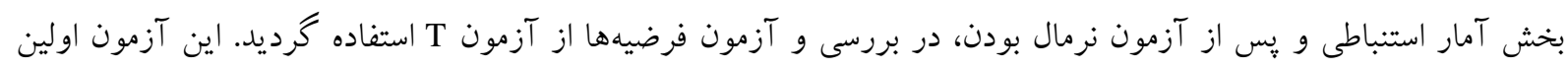

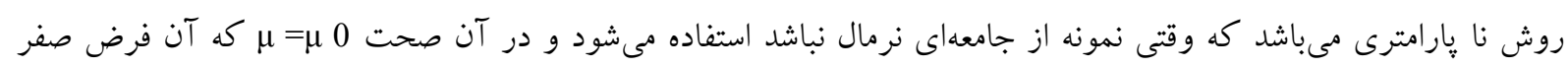

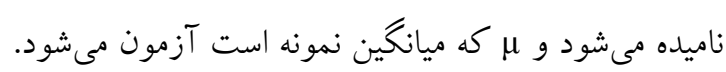

يافتههاى تحقيق شاخصهاى تو سعه اقتصادى اثر گذار در تحقق شهر خلاق با جمع بندى شاخصها از مطالعات جهانى، شاخصهاى خلاقيت يورو، كشورى، منطقهاى و شهرى، شاخصهاى مهم شهر خلاق در ابعاد مختلف فرهنگى، سياسى، اجتماعى و اقتصادى كه در تلفيق توسعه بايدار شهرى و خلاقيت شهرى تأثير گذارند 


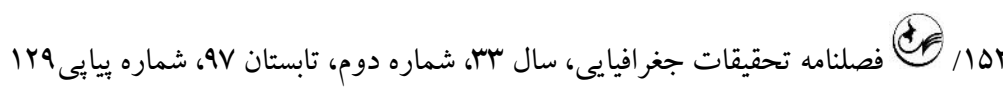

جدول - شاخص هاى شهر خلاق مؤثر در توسعه يايدار و خلاقيت شهرى

\begin{tabular}{|c|c|}
\hline & \\
\hline 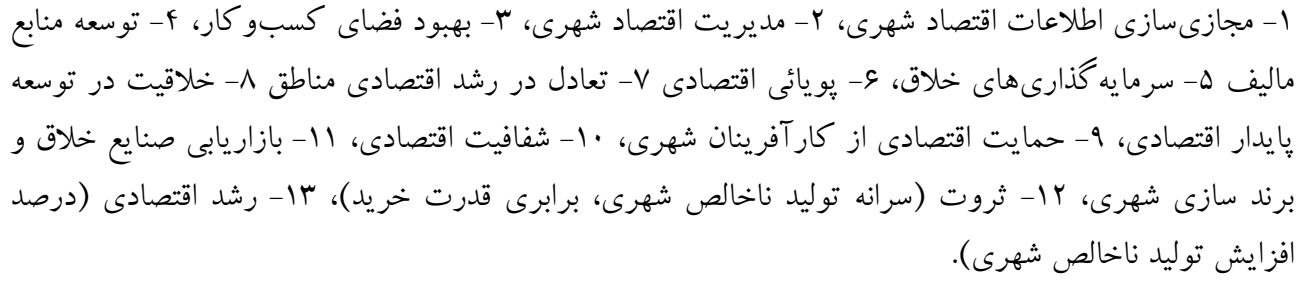 & \\
\hline 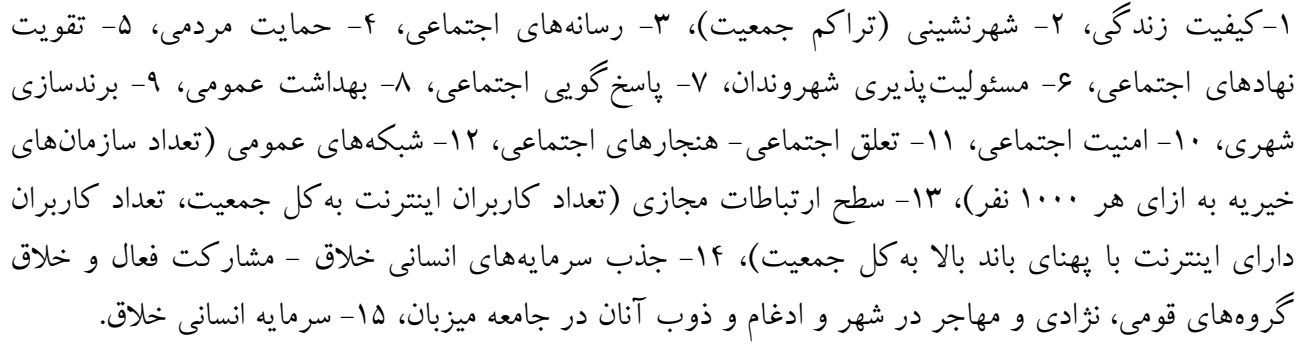 & \\
\hline 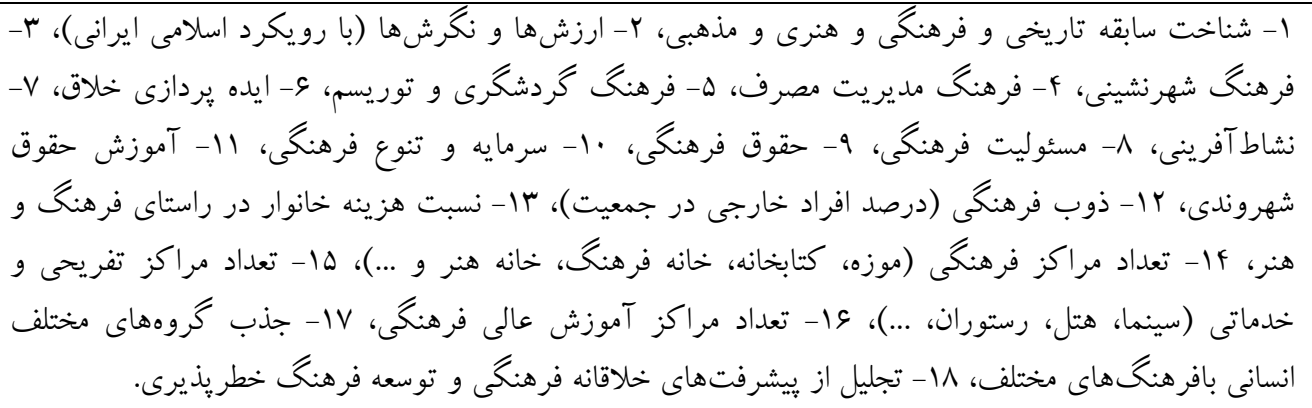 & \\
\hline 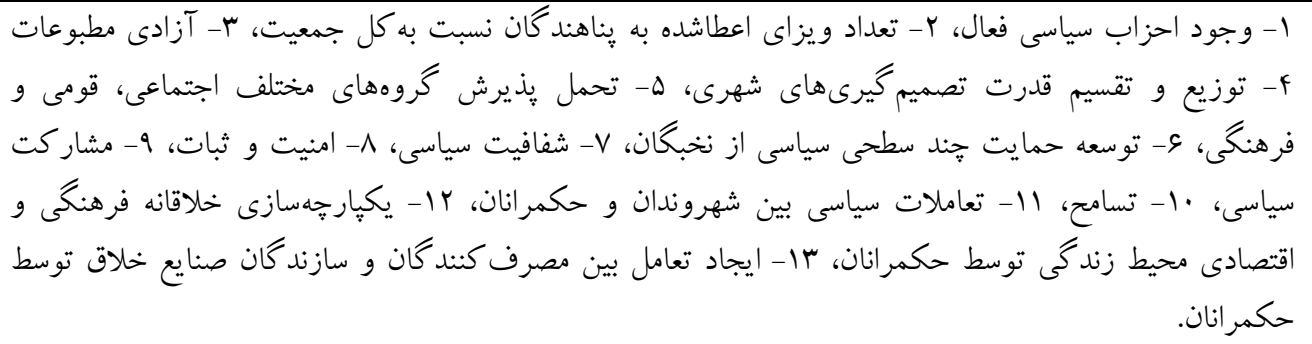 & \\
\hline
\end{tabular}

منبع: نغارند گان

\section{سنجش شاخصهاى تو سعه اقتصادى در تحقق شهر خلاق اصفهان از ديدگاه شهروندان}

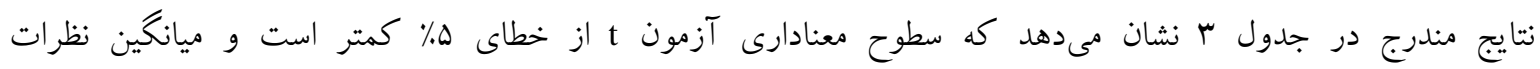

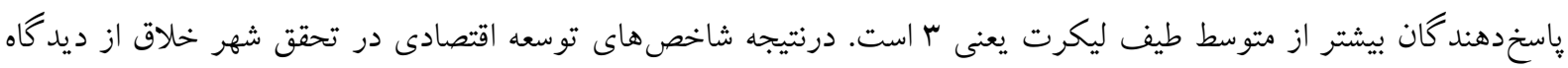

\section{جدول r-آزمون t در سنجش شاخص اقتصادى از ديدكاه شهروندان}

\begin{tabular}{|c|c|c|c|}
\hline $\mathrm{p}$ & درجه آزادى & t & شاخص \\
\hline$\cdot / \cdots$ & rA & $|s / Y|$ & بهبود فضاى كسبو كار شهروندان (توسط مديريت شهرى) \\
\hline$\cdot / \ldots$ & r r & $1 Q / A F$ & بازاريابى صنايع خلاق و برندسازى شهرى (توسط مديريت شهرى) \\
\hline$\cdot / \ldots$ & r & $19 / 81$ & مديريت يكيارجه اقتصاد شهرى (ارتباط شهروند محور نهادهاى مالى شهرى) \\
\hline$\cdot / \ldots$ & r & $r / / W$ & بُعد اقتصادى \\
\hline
\end{tabular}


سنجش شاخصهاى تو سعه اجتماعى در تحقق شهر خلاق اصفهان از ديدگاه شهروندان

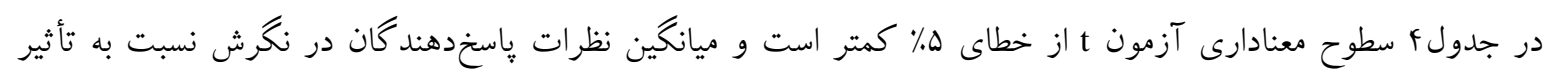

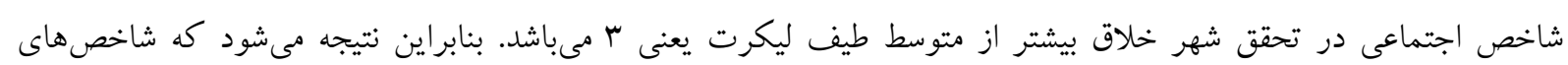
توسعه اجتماعى نيز در تحقق شهر خلاق از ديد كاه شهروندان مؤثر هستند.

\begin{tabular}{|c|c|c|c|}
\hline $\mathrm{p}$ & درجه آزادى & 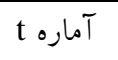 & 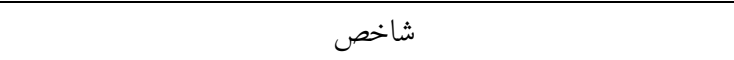 \\
\hline$\cdot / \cdots$ & $r \wedge r$ & $r s / r T$ & مسئوليت קيذيرى شهروندان (در برابر شهر) \\
\hline$\%$ & rAr & $r s / r \mu$ & تقويت نهادهاى اجتماعى (توسعه و ترويج ابتكارات گروهى) \\
\hline.$\cdots$ & rیr & $r \Delta / r s$ & سرمايه انسانى خلاق (استفاده بهينه از تفكرات طبقه خلاق شهر) \\
\hline.$/ \ldots$ & rیr & $r s / \mathrm{VV}$ & بُعد اجتماعى \\
\hline
\end{tabular}

سنجش شاخص هاى تو سعه فرهنگى در تحقق شهر خلاق اصفهان از ديدگاه شهروندان

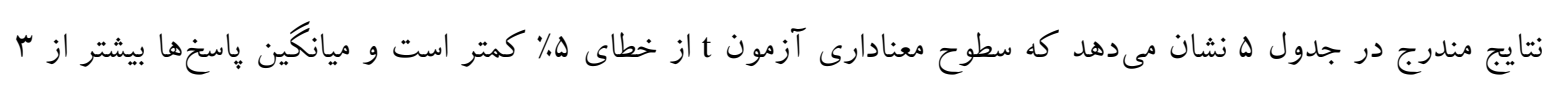
مىباشد كه نشان مىدهد شاخصهاى توسعه فرهنكى در تحقق شهر خلاق از ديد كاه شهروندان مؤثر هستند. جدول 0- آزمون t در سنجش شاخص فرهنكى از ديدكاه شهروندان

\begin{tabular}{|c|c|c|c|}
\hline $\mathrm{p}$ & درجه آزادى & 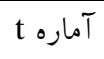 & 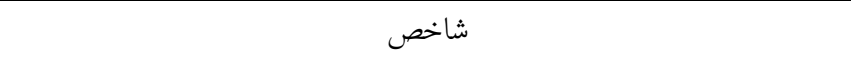 \\
\hline.$/ \ldots$ & r & $19 / 10$ & 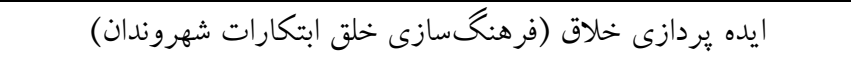 \\
\hline$\cdot / \ldots$ & r r & rM/Fr & فرهنگ مديريت مصرف (فرهنگسازى استفاده بهينه از منابع شهر) \\
\hline$\cdot / \ldots$ & $r \Delta \mu$ & $r \Delta / 19$ & سرمايه و تنوع فرهنگى(فرهنگ سازى استفاده از تنوع فرهنكى شهروندان) \\
\hline.$/ \ldots$ & r r & $\mu / / .$. & 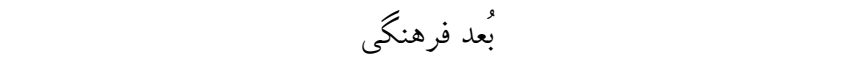 \\
\hline
\end{tabular}

سنجش شاخصهاى تو سعه سياسى در تحقق شهر خلاق اصفهان از ديدگاه شهروندان

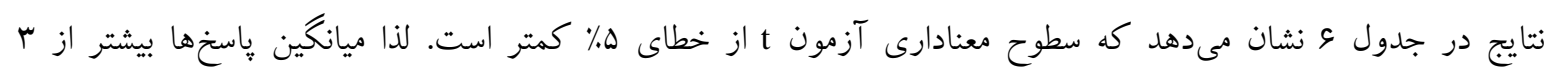

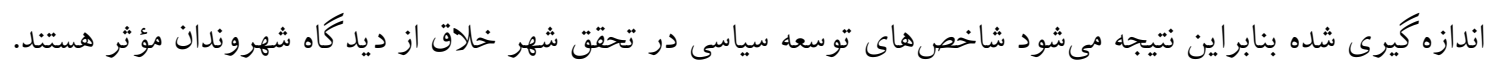

جدول 7- آزمون t در سنجش شاخص سياسى از ديد كاه شهروندان

\begin{tabular}{|c|c|c|c|}
\hline $\mathrm{p}$ & درجه آزادى & t آماره & 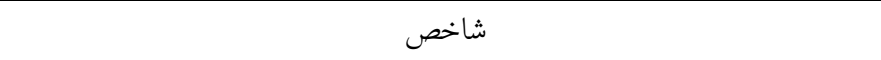 \\
\hline.$/ \ldots$ & $r \wedge r$ & rY/VS & امنيت و ثبات (ايجاد آرامش و امنيت در شهروندان توسط حكمرانان شهرى) \\
\hline$\cdot / \ldots$ & $r \Delta r$ & $1 F / 9 \mathrm{~T}$ & تسامح (مدارا، عدم دخالت، حلم و بردبارى حندجانبه حاكميت و مردم) \\
\hline$\cdot / \ldots$ & rی & IN/AV & شفافيت سياسى(دسترسى به اطلاعات و ارتباطات بين نهادهاى حاكميتى) \\
\hline.$/ \ldots$ & rлr & $r \mu / l f$ & 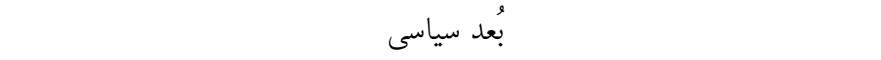 \\
\hline
\end{tabular}

نمايش مدل و نمودارها

با توجه به اين كه هدف اصلى اين تحقيق تأكيد براثر بخش بودن الكوهاى توسعه در مبحث شهرهاى خلاق بود با رسم يكى مدل

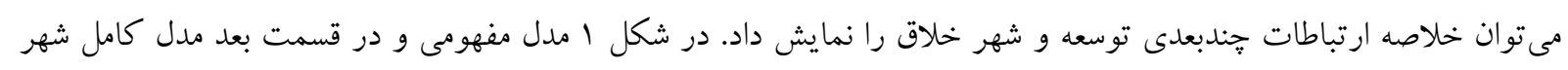




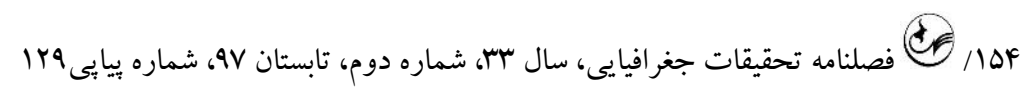
خلاق و ارتباط آن با الكوهاى توسعه و نيز در شكل بـ مهمترين شاخصهاى جمع آورىشده نشان دادهده است. متغير مستقل،

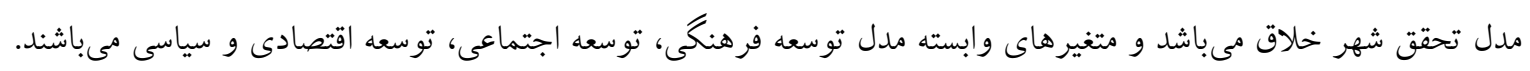

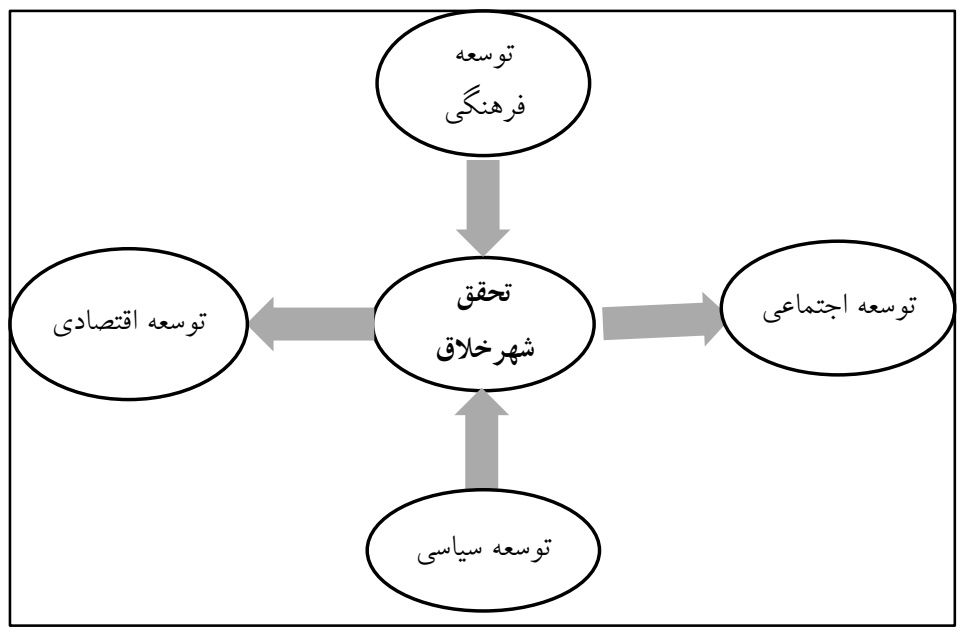

$$
\text { شكل 1- مدل مفهومى تحقيق يافتهاى يُوهش }
$$

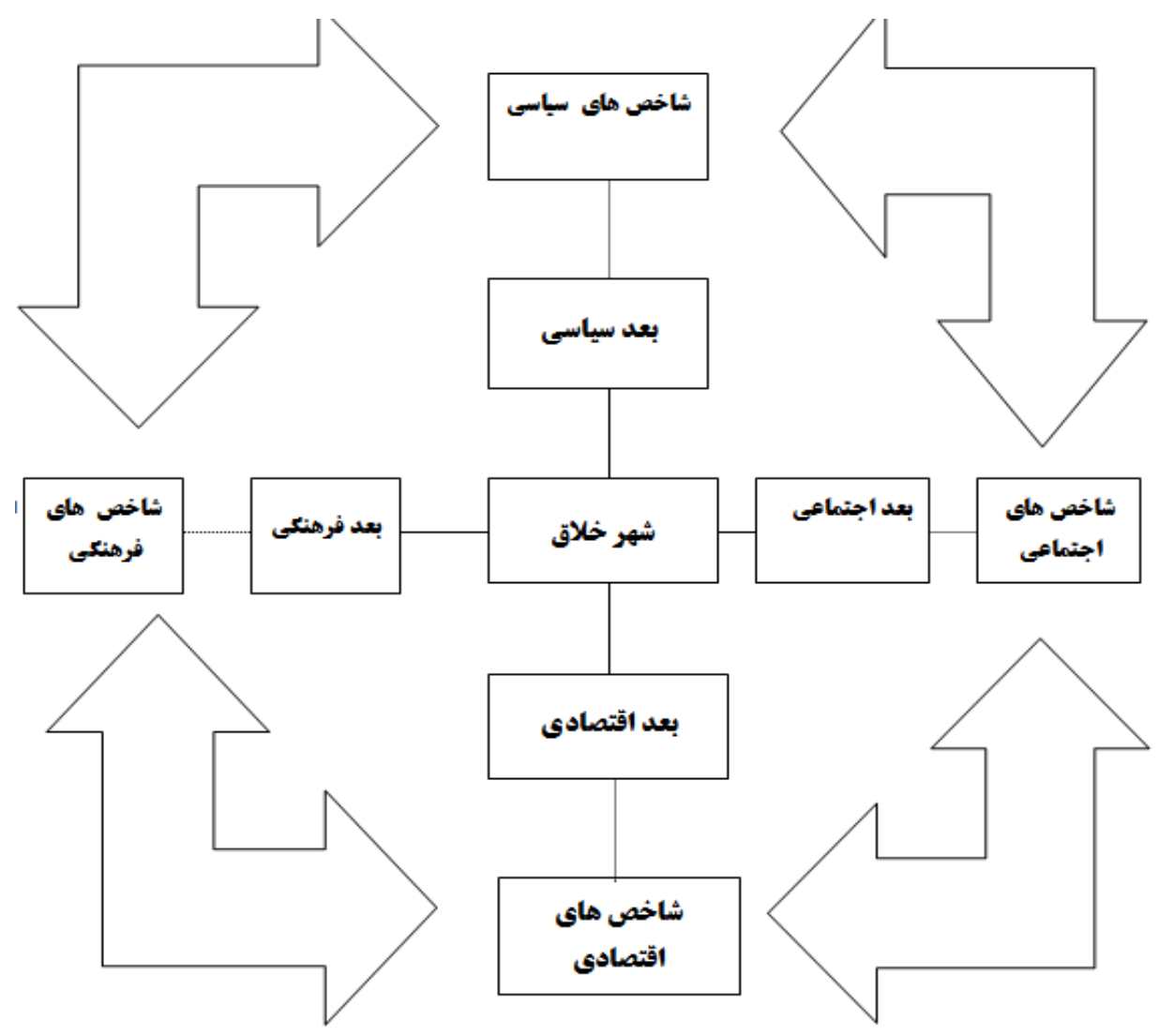

شكل r- مدل كامل شهر خلاق و ارتباطات شاخصها

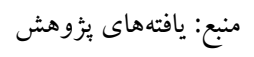




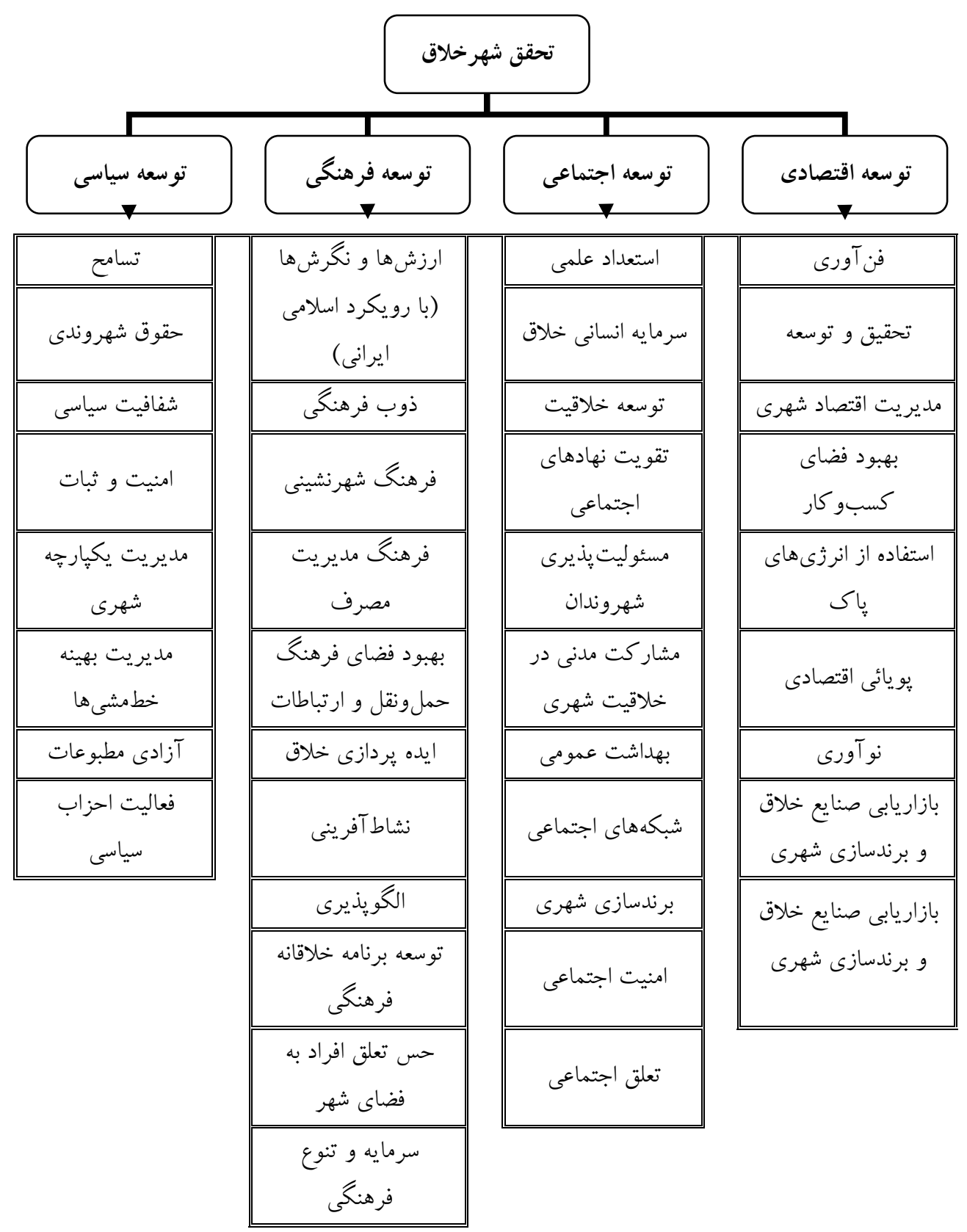

شكل r- شاخصهاى توسعه شهر خلاق اصفهان

در بررسى توصيفى شاخصهاى يزوهش از ديد كاه شهروندان، سه شاخص از مهمترين شاخصهاى ابعاد توسعه اقتصادى،

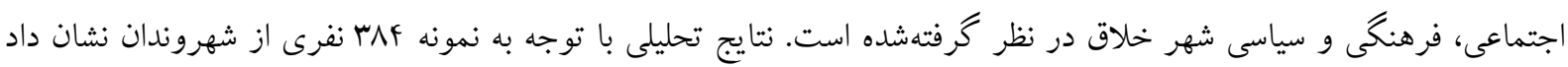

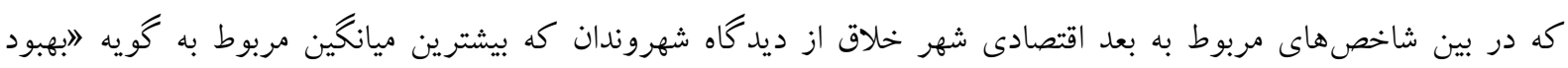

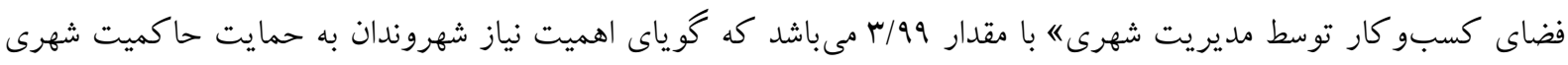

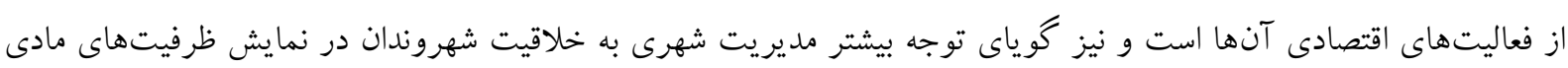

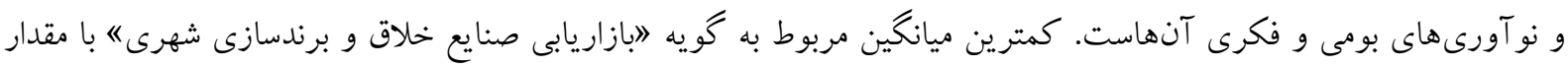

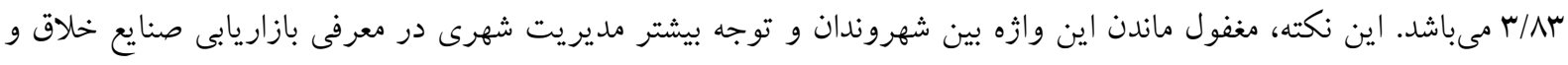


برندسازى را براى شهروندان بيشازييش نشان مىدهد. ميانخين كليه گويهها بهطور قابل توجهى از متوسط ب بيشتر هستند و اين

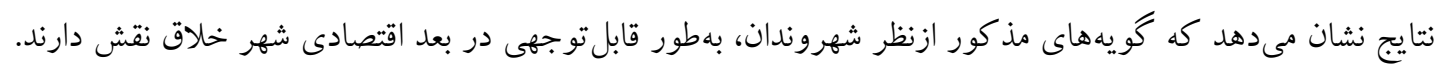

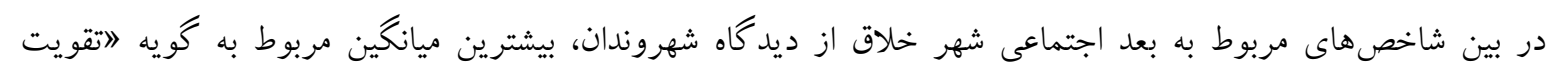

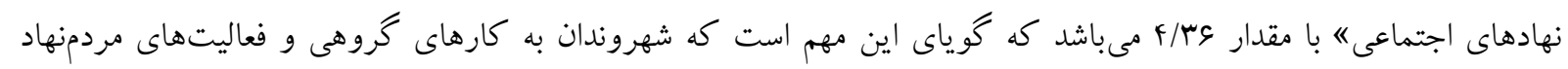

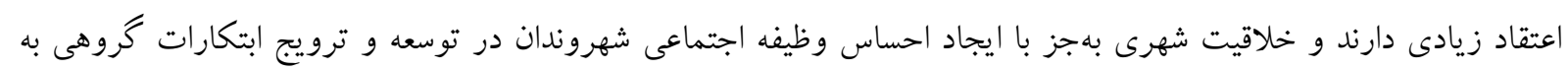

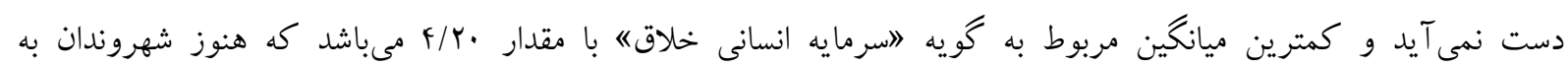

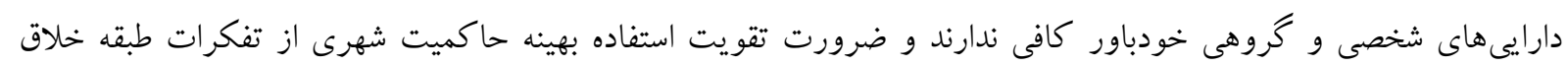

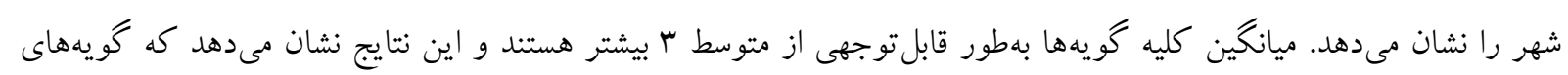

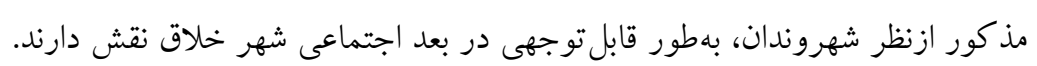

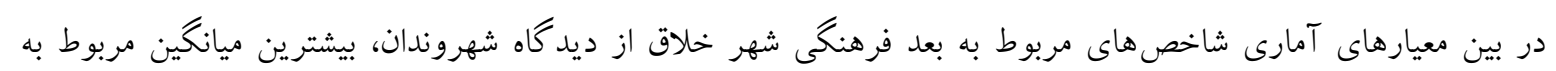

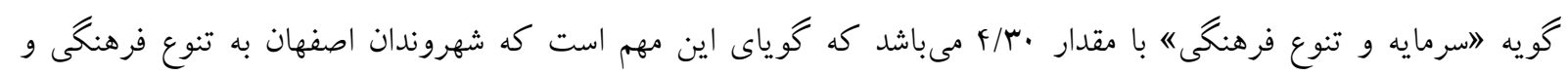

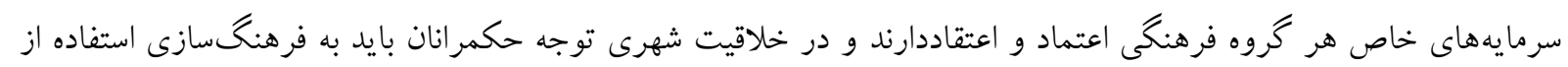

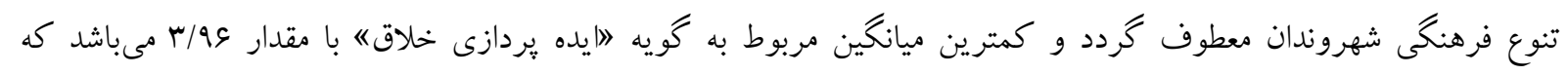

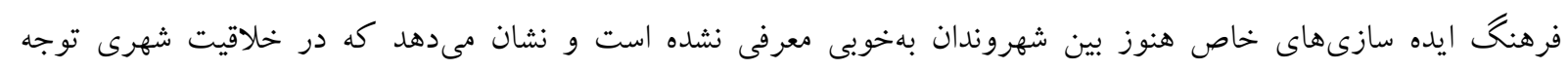

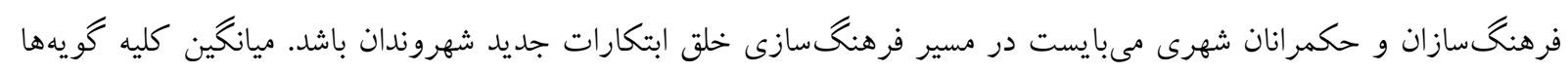

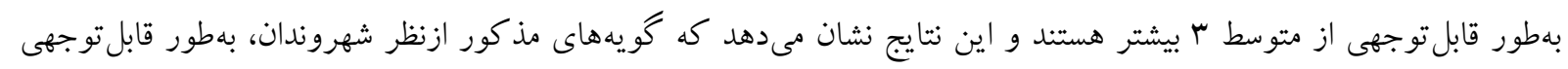

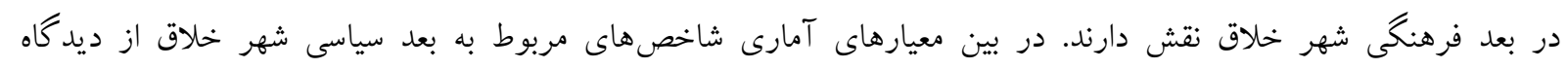

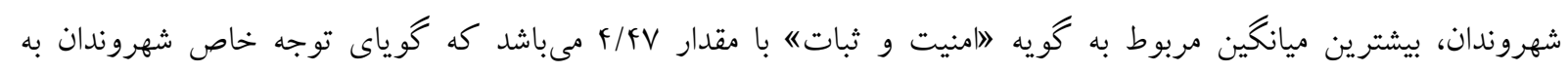

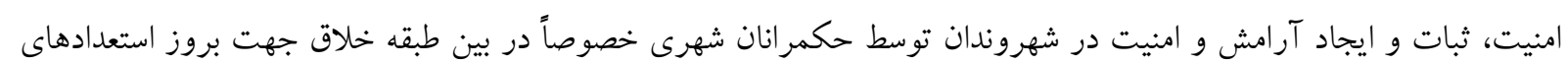

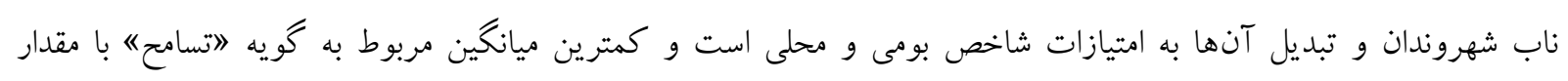

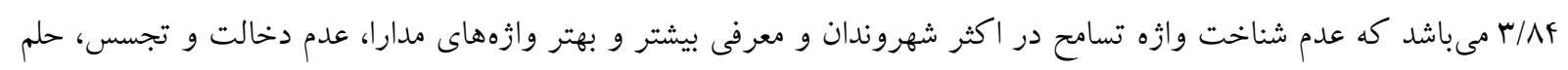

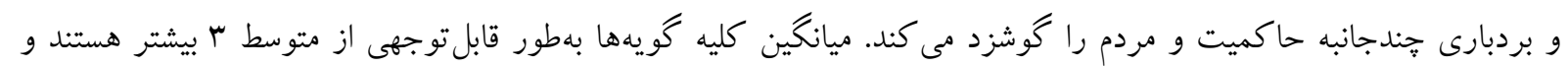

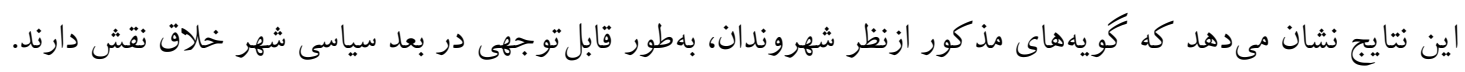

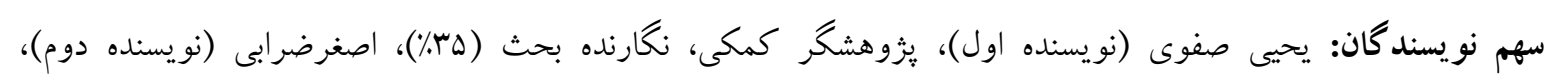

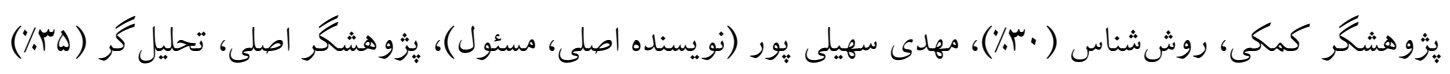

Atefi, H., \& Hatamialamdari, I. (2017). The effect of creative city indicator on the economic and social scale of metropolises (case study: Tabriz metropolis). Journal of Environmental Studies Haft Hesar, 6(22), 17 30. (Persian)

Batabyal, A. A., \& Beladi, H. (2016). The effects of probabilistic innovations on Schumpeterian economic growth in a creative region. Economic Modelling, 53, 224-230 .[DOI:10.1016/j.econmod.2015.11.026]

Bolívar, M., \& Rodríguez, P. (2018). Creative citizenship: the new wave for collaborative environments in smart cities. Academia Revista Latinoamericana de Administración, 31(1), 277-302 .[DOI:10.1108/ARLA04-2017-0133]

Borén, T., \& Young, C. (2017). Artists and creative city policy: Resistance, the mundane and engagement in Stockholm, Sweden. City, Culture and Society, 8, 21-26 .[DOI:10.1016/j.ccs.2016.05.002]

Branscomb, L .M., Kodama, F., \& Florida, R. (1999). Industrializing knowledge: University-industry linkages in Japan and the United States. Cambridge: MIT Press. 
Dorostkar, A., Farah, H., \& Majedi, H. (2016). Feasibility study on the formation of a creative area with industrial tourism theory (case study: Yazd city). Geography and Development Magazine, 14(45), 1940. (Persian)

Goldberg-Miller, S. B. D. (2018). Keeping creativity downtown: Policy learning from San Francisco, Seattle, and Vancouver for municipal cultural planning in Toronto. The Journal of Arts Management, Law, and Society, 48(3), 170-190 .[DOI:10.1080/10632921.2017.1422834]

Izadi, P., Hadiani, Z., Hajinejad, A., \& Ghaderi, J. (2016). Urban regeneration with emphasis on identification of creative city indicators (case study: Shiraz city). Quarterly Journal of Economics and Urban Management, 5(2), 21-40. (Persian)

Kakiuchi, E. (2016). Culturally creative cities in Japan: Reality and prospects. City, Culture and Society, 7(2), 101-108 .[DOI:10.1016/j.ccs.2015.11.003]

Landry, C., \& Bianchini, F. (1995). The creative city (First ed. Vol. 12). London: Demos in Association with Comedia.

Musterd, S. (2004). Amsterdam as a creative cultural knowledge city: Some conditions. Built Environment, 30(3), 225-234 .[DOI:10.2148/benv.30.3.225.54307]

Nazmfar, H., Alavi, S., \& Eshghi, A. (2017). Measuring the ranking of urban settlements of Ardabil province in terms of possessing the creative city index. Geogrphy and Environmental Planning, 28(2), 167-184. (Persian)

Pourahmad, A., Hamidi, A. S., Farhadpour, A., \& Hoseinpour, M. (2017). Assessing the challenges and opportunities of creating a creative city in free trade zones (case study: Aras Free Trade area). Human Settlement Planning Studies, 11(37), 1-19. (Persian)

Pourramezan, I., Pourhosein Roshan, H., \& Aliakbary, S. (2016). City of knowledge: Future development strategy of Zanjan city as a sustai. Quarterly Journal of Environmental Based Territorial Planning, 9(35), 171-192. (Persian)

Rabbani Khorasgani, A., Rabbani Khorasgani, R., Adibi Sedeh, M., \& Moazzeni, A. (2012). Investigating the role of social diversity in the creation of creative cities (case study: Isfahan city). Geography and Development Magazine, 9(21), 159-180. (Persian)

Sandercock, L. (2005). Interface: A new spin on the creative city: artist/planner collaborations. Planning Theory \&Practice, 6(1), 101-103 .[DOI:10.1080/1464935042000334985]

Sarvar, R., Akbari, M., Amani, M., \& Taleshianbouhi, M. (2016). Analysis of the efficiency of urban neighborhoods in terms of indicators of the creative city (case study: Bonab city). Quarterly Journal of International Geographical Society of Iran, 14(48), 322-351. (Persian)

Shaterian, M., Heydari, R., \& Vorfinejad, j. (2017). The effects of tourism power on infrastructure development and the creation of a creative city (case study: Kermanshah city). Journal of Research, International and International Association of Geographic Society of Iran, 15(52), 201-216. (Persian)

Thiel, J. (2017). Creative cities and the reflexivity of the urban creative economy. European Urban and Regional Studies, 24(1), 21-34 .[DOI:10.1177/0969776415595105]

Yigitcanlar, T., \& Kamruzzaman, M. (2018). Does smart city policy lead to sustainability of cities? Land Use Policy, 73, 49-58 .[DOI:10.1016/j.landusepol.2018.01.034]

Zarrabi, A., Mousavi, N., \& Bagherikashkouli, A. (2014). Investigating the realizability of creative city (case study: cities of Yazd province .,(Journal of Geography and Urban Space Development, 1(1), 1-17. (Persian) 